\title{
Identification of a Peptide Produced by Bifidobacterium longum CECT 7210 with Antirotaviral Activity
}

\author{
Empar Chenoll', Beatriz Casinos ${ }^{1}$, Esther Bataller ${ }^{1}$, Javier Buesa ${ }^{2}$, Daniel Ramón ${ }^{1}$, \\ Salvador Genovés ${ }^{1}$, Joan Fábrega ${ }^{3}$, Montserrat Rivero Urgell ${ }^{3}$ and \\ José A. Moreno Muñoz ${ }^{3 *}$ \\ ${ }^{1}$ Department of AgroFood Biotechnology, Biópolis S.L., Valencia, Spain, ${ }^{2}$ Department of Microbiology, School of Medicine, \\ University of Valencia - Hospital Clínico Universitario, Valencia, Spain, ${ }^{3}$ Laboratorios Ordesa S.L., Barcelona, Spain
}

Rotavirus is one of the main causes of acute diarrhea and enteritis in infants. Currently, studies are underway to assess the use of probiotics to improve rotavirus vaccine protection. A previous work demonstrated that the probiotic strain Bifidobacterium

OPEN ACCESS

Edited by:

Andrea Gomez-Zavaglia,

Center for Research

and Development in Food

Cryotechnology - Consejo Nacional

de Investigaciones Cientificas

y Técnicas, Argentina

Reviewed by:

Young Min Kwon,

University of Arkansas, USA

Paula Carasi,

Universidad Nacional de La Plata,

Argentina

*Correspondence:

José A. Moreno Muñoz josea.moreno@ordesa.es

Specialty section:

This article was submitted to

Food Microbiology,

a section of the journal

Frontiers in Microbiology

Received: 15 February 2016 Accepted: 19 April 2016

Published: 04 May 2016

Citation:

Chenoll E, Casinos B, Bataller E,

Buesa J, Ramón D, Genovés S,

Fábrega J, Rivero Urgell M

and Moreno Muñoz JA (2016)

Identification of a Peptide Produced

by Bifidobacterium longum CECT

7210 with Antirotaviral Activity.

Front. Microbiol. 7:655.

doi: 10.3389/fmicb.2016.00655 longum subsp. infantis CECT 7210 is able to hinder rotavirus replication both in vitro and in vivo. The present study takes a systematic approach in order to identify the molecule directly involved in rotavirus inhibition. Supernatant protease digestions revealed both the proteinaceous nature of the active substance and the fact that the molecule responsible for inhibiting rotavirus replication is released to the supernatant. Following purification by cationic exchange chromatography, active fractions were obtained and the functional compound was identified as an 11-amino acid peptide (MHQPHQPLPPT, named 11-mer peptide) with a molecular mass of $1.282 \mathrm{KDa}$. The functionality of 11 mer was verified using the synthesized peptide in Wa, Ito, and VA70 rotavirus infections of both HT-29 and MA-104 cell lines. Finally, protease activity was detected in B. longum subsp. infantis CECT 7210 supernatant, which releases 11-mer peptide. A preliminary identification of the protease is also included in the study.

Keywords: B. longum subsp. infantis CECT 7210, probiotics, rotavirus, 11-mer peptide, protease

\section{INTRODUCTION}

Group A rotavirus is one of the major causes of acute gastroenteritis in infants and young children, leading to an estimated 2 million hospitalizations per year (Parashar et al., 2006). Despite the administration of rotavirus vaccines, rotavirus still accounts for an estimated 21.3$39.5 \%$ of the hospital admissions for diarrheal disease in Europe (Williams et al., 2009). However, hospitalizations of older children and adults for diarrhea have greatly decreased after the introduction of infant rotavirus vaccination, which suggests that some rotavirus episodes were transmitted from infants (Lopman et al., 2011). Rotaviruses are transmitted by the fecal-oral route, inducing diarrhea due to malabsorption by the infected epithelial cells of the intestinal mucosa (Kapikian et al., 2001) and increased intestinal motility (Istrate et al., 2014). The mechanisms underlying diarrhea include secondary malabsorption, patchy lesions, villous atrophy, and disruption of the tight junctions in the small intestine, altered ion channel transport due to the secretion of neurotransmitters (Hagbom et al., 2012), NSP4 toxicity (Hodges and Gill, 2010), the activation of the enteric nervous system (Lundgren et al., 2000), and the expression of aquaporins (Cao et al., 2014). The process is characterized by profuse diarrhea, which can 
cause severe dehydration and, in the case of non-intervention, lead to death (Parashar et al., 2006). Several vaccines have been developed, demonstrating different degrees of protection against rotavirus infection (Vesikari et al., 2007; Dennehy, 2008; Glass et al., 2014). Nevertheless, it has been reported that despite wide coverage, the antibodies induced by vaccination cannot totally prevent symptomatic infections of some rotavirus genotypes (Bucardo et al., 2015). These findings imply that new generation vaccines and complementary preventive approaches are needed to decrease the morbidity and mortality associated with rotavirus diarrhea (Demirjian and Levy, 2009; Glass et al., 2014).

During the last few years, research has focused on the potential use of probiotics as preventive agents against rotavirus. The Food and Agriculture Organization (FAO) and the World Health Organization (WHO) define probiotics as "live microorganisms which when administered in adequate amounts confer a health benefit on the host" (FAO/WHO, 2001). These microorganisms are demonstrated to be effective in preventing several disorders such as infections, diarrhea, and inflammatory diseases (Reid, 2008; Kotzampassi and Giamarellos-Bourboulis, 2012). Moreover, probiotics affect the modulation and establishment of intestinal microbiota and enhance maturation of the innate and adaptive immune systems among others (Kotzampassi and Giamarellos-Bourboulis, 2012). Regarding the efficacy of these microorganisms in treating rotavirus-related diarrhea, a number of probiotics have been reported including Bifidobacterium longum and Lactobacillus acidophilus strains (Lee et al., 2014) and commercial probiotic strains such as Lactobacillus GG (Sindhu et al., 2014). Nevertheless, most of these reports are based on the amelioration of diarrhea symptoms but little has been published on the identification of the mechanisms and molecules underlying rotavirus inhibition. In this respect, current ideas regarding these mechanisms of action include changes in gut ecology, an effect on the gut mucosal barrier, and a modulation of the immune response (Kotzampassi and Giamarellos-Bourboulis, 2012), each being strain-specific (Oelschlaeger, 2010).

A previous study demonstrated that strain B. longum subsp. infantis CECT 7210 exerts a direct in vitro effect on rotavirus infection in HT-29 and MA-104 cell lines (Muñoz et al., 2011). Furthermore, an in vivo effect was shown to involve both antiviral effects and immunological enhancement, providing preliminary protection against the rotavirus infection in a mouse model. The strain was also characterized, demonstrating that B. longum subsp. infantis CECT 7210 fulfills the main criteria required for consideration as a probiotic. However, the interaction of the probiotic with the host cell surface alone did not explain all the mechanisms involved, since infection levels decreased even when the probiotic was added directly to the virus, therefore further studies must be conducted to establish the mechanisms involved in the antiviral effect of this probiotic strain.

Thus, the aim of this study is to identify the molecule(s) directly responsible for the activity of strain B. longum subsp. infantis CECT 7210 against rotavirus and to investigate the mechanism underlying the inhibition.

\section{MATERIALS AND METHODS}

\section{Cells and Viruses}

The human colon carcinoma cell line HT-29 was grown in Dulbecco's modified minimal essential medium (DMEM) supplemented with $10 \%$ (v/v) fetal bovine serum (FBS, Gibco Invitrogen, Paisley, UK). The Rhesus monkey kidney cell line MA-104 was grown in Eagle's minimal essential medium (MEM) supplemented with $10 \%(\mathrm{v} / \mathrm{v})$ FBS. Human rotavirus strain Wa (G1-P1A[8]) and simian rotavirus strain SA11 (G3-P1A[8]) were obtained from the American Type Culture Collection. Human rotavirus strain VA70 (G4-P1A[8]) and porcine rotavirus strain Ito (G3-P1A[8]) were a gift from Prof. Albert Bosch (University of Barcelona, Spain). B. longum subsp. infantis CECT 7210 is a probiotic strain isolated from baby's feces and identified and characterized previously by Muñoz et al. (2011)

\section{Rotavirus Propagation and In Vitro Inhibition Assays}

Assays were carried out as in Muñoz et al. (2011). Competition assays were performed with rotavirus SA11, Ito, VA70 and Wa in both HT-29 and MA-104 cell lines. In all cases, cell monolayers were grown in 96-well plates and the tested compounds were incubated with rotavirus followed by the infection of the cells with this virus-compound mixture (strategy A) or the compound was incubated with the cell cultures followed by the inoculation of the virus (strategy B). In both cases, viral antigens were detected by immunoperoxidase assays (Muñoz et al., 2011). Infectious peroxidase-stained foci were counted and arithmetic means were calculated to determine the number of foci per microscopic field, which were compared with the number of infectious foci of untreated virus controls to obtain the reduction percentage of virus focus-forming units. The identified peptide was synthesized at $90 \%$ purity (Genscript Corporation, Piscataway, NJ, USA) and its activity was measured for both strategies at different concentrations $(1,5,10$, and $50 \mu \mathrm{M})$.

\section{Purification and Identification of the Substance/s of Interest by Cationic Exchange Chromatography Followed by Reverse-Phase Chromatography}

\section{Supernatant Processing}

A volume of $10 \mathrm{~L}$ culture of the strain B. longum subsp. infantis CECT 7210 growing in MRS (de Man, Rogosa, and Sharpe, CM1153, Oxoid, Basingstoke, UK) medium supplemented with cysteine $(0.05 \% \mathrm{w} / \mathrm{v}$; MRSC) was obtained and centrifuged at $12,000 \times g$ for $15 \mathrm{~min}$ at $4^{\circ} \mathrm{C}$. Supernatant was neutralized to pH 6.5 with $\mathrm{NaOH}(10 \mathrm{~N}), 10 \mathrm{x}$ concentrated by freeze-drying and sterilized by $0.22-\mu \mathrm{m}$-pore-size filter (Minisart hydrophilic syringe filter; Sartorius Stedim Biotech $\mathrm{GmbH}$, Gottingen, Germany). Concentrated supernatant was stored at $-20^{\circ} \mathrm{C}$ until use.

\section{Identification of the Nature of the Active Compound}

In order to study, the nature of the substance of interest, the freeze-dried samples were treated with lipase and proteases 
(proteinase $\mathrm{K}$ and pepsin). To study the effect of lipase, a freeze-dried sample (from $25 \mathrm{~mL}$ supernatant) was re-suspended in $2.4 \mathrm{~mL}$ phosphate buffer solution $(50 \mathrm{mM}, \mathrm{pH} 6.9)$, then $0.1 \mathrm{~mL}$ lipase from porcine pancreas was added $(50 \mathrm{mg} / \mathrm{mL}$; Sigma-Aldrich). The mixture was incubated at $37^{\circ} \mathrm{C}$ for $2 \mathrm{~h}$, and the reaction was inactivated taking the solution to $\mathrm{pH}$ 4.5. Regarding pepsin, a freeze-dried sample (from $25 \mathrm{~mL}$ supernatant) was re-suspended in $1.25 \mathrm{~mL}$ of McIlvaine buffer $50 \mathrm{mM} \mathrm{pH} 4.0$, to which $0.109 \mathrm{~mL}$ of a pepsin solution was added (50 mg/mL; Sigma-Aldrich, St. Louis, MO, USA). This mixture was incubated at $37^{\circ} \mathrm{C}$ for $2 \mathrm{~h}$, and the reaction was inactivated taking the solution to $\mathrm{pH} 6.5$ in a final volume of $2.5 \mathrm{~mL}$. In the case of proteinase $\mathrm{K}$, freeze-dried sample (from $25 \mathrm{~mL}$ supernatant) was re-suspended in $2.4 \mathrm{~mL}$ of phosphate buffer $50 \mathrm{mM} \mathrm{pH} 6.5$, to which $0.1 \mathrm{~mL}$ of a proteinase $\mathrm{K}$ solution was added (50 mg/mL; Sigma-Aldrich). This mixture was incubated at $37^{\circ} \mathrm{C}$ for $2 \mathrm{~h}$, and then proteinase $\mathrm{K}$ was inactivated by incubation at $100^{\circ} \mathrm{C}$ for $15 \mathrm{~min}$. Analysis of the inhibition of proliferation of rotavirus SA11 was performed in all processed supernatants.

The negative controls included in these tests were supernatant of culture medium MRSC without inoculation (C1) and the same supernatant incubated for $2 \mathrm{~h}$ at $37^{\circ} \mathrm{C}$ (QC3). Control with noninactivated proteinase $\mathrm{K}$ supernatant could not be tested due to post-incubation cell lysis. As a negative control of inhibition, a non-fermented freeze-dried sample was used (C1). As positive control of infection, a solution containing cells and viruses was used.

\section{Purification and Identification of the Substance Active against Rotavirus}

Purification was performed following Chenoll et al. (2011). Briefly, the supernatant was added to sodium phosphate buffer (20 mM, pH 5.8) and then applied to a cationic exchange column (HiPrep 16/10 SP FF, GE Healthcare, Amersham Biosciences $\mathrm{AB}$, Sweden) by means of a chromatography system (ÄKTA Explorer, Amersham Pharmacia Biotech). All those proteins of cationic nature adsorbed were then eluted with sodium phosphate buffer (20 mM, pH 5.8) and equilibrated with $\mathrm{NaCl}$ $1 \mathrm{M}$ without gradient. The proteins were eluted simultaneously in a few fractions in minimal volume $(10 \mathrm{~mL})$. Each collected fraction was subjected to an ultrafiltration process using 5,000 Da filters (Extreme Amicon, Millipore, Billerica, MA, USA) followed by another stage of reverse phase chromatography with a RESOURCE RPC $3 \mathrm{~mL}$ column (GE Healthcare). An aliquot of these fractions was taken to dryness to eliminate the dissolvent and re-suspended in a volume of MEM buffer (Sigma-Aldrich) just before performing in vitro inhibition assays. In total, 28 fractions were selected for rotavirus inhibition assays (strategy B) with SA11 virus in MA-104 cell line as explained above. The fractions that gave a positive inhibition result were analyzed by MALDI-TOF peptide mass fingerprinting at the "Centro Nacional de Investigaciones Cardiovasculares" (CNIC, Madrid, Spain), to determine the molecular weight(s) of the peptide(s) present in each fraction. Sequences obtained were compared against the database of proteins/peptides by means of the BLAST online tool.

\section{Purification and Identification of the Protease Supernatant Processing}

A volume of $1 \mathrm{~L}$ culture of strain B. longum subsp. infantis CECT 7210 in MRSC medium was obtained and centrifuged at $12,000 \times g$ for $15 \mathrm{~min}$ under refrigerated conditions. Proteins were precipitated by the addition of ammonium sulfate ( $80 \%$ saturation) and collected by centrifugation $(30 \mathrm{~min}$, $12,000 \times g$ ). Pellet was resuspended in Tris- $\mathrm{HCl}$ buffer (Tris$\mathrm{HCl} 20 \mathrm{mM}, \mathrm{pH}$ 8.5), dialyzed with a $10 \mathrm{KDa}$ membrane at $4^{\circ} \mathrm{C}$ and applied to an anionic exchange column (HiPrep 16/10 Q XL, GE Healthcare) by means of a chromatographic system (ÄKTA Explorer). Anionic proteins were eluted with buffer Tris- $\mathrm{HCl}$ (20mM, pH 8.5, $\left.\mathrm{CaCl}_{2} 5 \mathrm{mM}\right)$ using a gradient of $\mathrm{NaCl}$ from 0 to $1 \mathrm{M}$. As an indicator of the purification process, samples were monitored at $280 \mathrm{~nm}$ throughout elution and protease activity measured with BSA as a substrate following Bradford (1976). Protease-positive fractions were then concentrated by $10 \mathrm{KDa}$ ultrafiltration (Millipore), diluted with distilled water and applied to gel filtration chromatography ( $1 \%$ column volume) with a HiLoad Superdex 75 prep grade column (GE Healthcare Europe GmbH, Barcelona, Spain) with fractionation in a range of 3,000$70,000 \mathrm{Da}$. Sample was monitored with absorbance at $280 \mathrm{~nm}$, and fractions with proteins were collected, desalted by PD10 columns (GE Healthcare Life Sciences) and concentrated by $10 \mathrm{KDa}$ ultrafiltration. A volume of $30 \mu \mathrm{L}$ of protease-positive fraction was electrophoresed on a $12.5 \%$ polyacrylamide SDSPAGE gel. Gel was stained with silver nitrate and a 2097.1 KDa commercial molecular weight marker (SDS-PAGE Standards, Broad Range) was used. The single band was separated and analyzed by MALDI-TOF peptide mass fingerprinting at CNIC, to determine the molecular weight and sequence of the protein. Sequence obtained was compared against the database of proteins/peptides by means of the BLAST online tool.

\section{Evaluation of 11-mer Production from $\beta$-Casein Using the Purified Protease}

In order to evaluate whether the purified protease hydrolyzes $\beta$-casein protein to obtain 11-mer peptide, an enzymatic activity assay was performed with $\beta$-casein as substrate and purified protease from CECT 7210 supernatant as enzyme. The hydrolysis was carried out in a solution containing $15 \mathrm{ml}$ of protease-purified fraction $(0.04 \mathrm{U}), 30 \mathrm{~mL}$ of $2 \% \beta$-casein solution (BioUltra, Sigma-Aldrich) and $105 \mathrm{~mL}$ phosphate

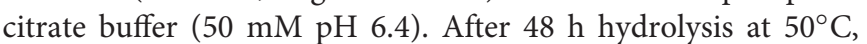
samples were boiled for $10 \mathrm{~min}$ and peptides formation was analyzed by HPLC. Evaluation of 11-mer formation and $\beta$-casein degradation was conducted on a HPLC (Waters 2695) with photodiode array detector (Waters 2996) and C18 column

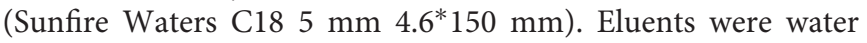
(MilliQ quality; A) and acetonitrile (90\% v/v; B), both with TFA $0.1 \%(\mathrm{v} / \mathrm{v})$. Chromatographic conditions are summarized in Table 1. 
TABLE 1 | HPLC chromatographic conditions used to quantify peptide 11-mer.

\begin{tabular}{lcc}
\hline Time (min) & \% Buffer A & \% Buffer B \\
\hline- & 100 & 0 \\
40 & 50 & 50 \\
42 & 0 & 100 \\
50 & 0 & 100 \\
60 & 100 & 0 \\
\hline
\end{tabular}

\section{Characterization of the Purified Protease Carbon Sources}

Protease activity was assayed in supernatants of strain CECT 7210 grown in MRSC media containing glucose, lactose or maltose as sole carbon source, respectively (all of them at $20 \mathrm{~g} / \mathrm{L}$ ). Protease activity was measured in supernatants after $17 \mathrm{~h}$ of growth and centrifuged at $12,000 \times g$ for $15 \mathrm{~min}$ under refrigerated conditions. BSA degradation $(1 \% \mathrm{w} / \mathrm{v}$, citrate-phosphate buffer $50 \mathrm{mM}, \mathrm{pH}$ 6.4) was measured at different incubation times $(1 \mathrm{~h}, 3 \mathrm{~h}$ and $5 \mathrm{~h}$ ) both with the supernatants and with $3 \mathrm{KDa}$ concentrated fractions. Using the supernatants and the $3 \mathrm{KDa}$ concentrated fractions, enzymatic reactions were performed with $\beta$-casein as substrate. Assays were performed as described above and $\beta$-casein degradation and 11-mer formation were monitored by HPLC.

\section{Optimum pH}

The protease assay was performed at different $\mathrm{pH}$ values with purified protease. A $\beta$-casein solution $(2 \% \mathrm{w} / \mathrm{v})$ was incubated with purified protease at $50^{\circ} \mathrm{C}$ (optimum temperature) for $72 \mathrm{~h}$. The hydrolysis reaction was carried out in a solution with purified protease $(10 \mathrm{~mL}), \beta$-casein solution $(2 \% \mathrm{w} / \mathrm{v} ; 20 \mathrm{~mL})$ and PBS buffer (70 mL), at $\mathrm{pH} 4,6,7,8$, and 10 . After incubation, samples were boiled for $10 \mathrm{~min}$ to stop the reaction, filtered through a Millipore $0.45 \mu \mathrm{m}$ pore-size filter and 11-mer peptide was analyzed by HPLC.

\section{Optimum Temperature}

The protease assay was performed with purified protease at different temperatures. The $\beta$-casein degradation assay was carried out as above, during $72 \mathrm{~h}$, at $\mathrm{pH} 6.4$ and at temperatures of $35,40,50$, and $60^{\circ} \mathrm{C}$. As in the case of $\mathrm{pH}$ studies, the amount of 11-mer peptide was analyzed by HPLC.

\section{Influence of Zinc, Potassium, and Calcium}

The influence of zinc, potassium, and calcium on the purified protease activity was studied. As above, the assay was carried out with $\beta$-casein $(2 \% \mathrm{w} / \mathrm{v})$ as substrate and $70 \mu \mathrm{L}$ citratephosphate buffer (pH 6.4, $50 \mathrm{mM}$ ). Incubation conditions were $50^{\circ} \mathrm{C}$ (optimum temperature) for $72 \mathrm{~h}$. Minerals were added separately at a final concentration of $10 \mathrm{mM}$. After incubation, samples were boiled and $0.45 \mu \mathrm{m}$ pore-size filtered, and 11mer was analyzed by HPLC. A control was included without the addition of any mineral.

\section{Statistical Analysis}

In all cases, results obtained were analyzed using GraphPad Prism 4 software (GraphPad software, La Jolla, CA, USA). Data were subjected to one-way analysis of variance (ANOVA). The Tukey's multiple comparison test was used for comparison of means.

\section{RESULTS}

\section{Purification and Identification of the Substance of Interest by Cationic Exchange Followed by Reverse-Phase Chromatography}

Identification of the Nature of the Active Compound

In order to determine the nature of the active compound responsible for inhibition of rotavirus, the freeze-dried samples were treated with proteinase K, pepsin and lipases. Non-treated CECT 7210 supernatant significantly decreased infection via either strategy A or B, by 51.6 and 83\%, respectively (Table 2). Analysis of rotavirus SA11 proliferation for the aliquots processed by lipases showed no changes in supernatant rotavirus inhibition values (data not shown). Supernatant treated with proteases showed no inhibition of rotavirus infection via either strategy A or B (Table 2) and confirmed the proteinaceous nature of the active compound.

\section{Purification and Identification of the Active Substance against Rotavirus}

The strategy used to identify the active substance against rotavirus started with its purification from the CECT 7210 active supernatant. To do this, a total of 28 fractions of reverse phase were selected for rotavirus inhibition assays (strategy B). Of these, only six fractions rendered a significant reduction in infected foci and were selected for further investigation. The selected fractions are summarized in Table 3. All the fractions that proved positive for inhibition were analyzed by MALDI-TOF peptide mass fingerprinting to determine the molecular weights of the peptide/s present in each fraction (results of each fraction are not shown). Analyzing all the spectra, the only common signal in all

TABLE 2 | Assay for in vitro activity against human rotavirus SA11 in MA-104 cell line in supernatants obtained with the growth of $B$. longum subsp. infantis CECT 7210, and treated.

\begin{tabular}{lcc}
\hline Assays & \multicolumn{2}{c}{ \% Focus of infection \pm SD } \\
\cline { 2 - 3 } & Strategy A & Strategy B \\
\hline Pepsin treated supernatant of CECT7210 & $134.6 \pm 26.7$ & $117.9 \pm 26.8$ \\
Proteinase K treated supernatant of CECT7210 & $117.9 \pm 33.4$ & $101.8 \pm 7.6$ \\
Untreated CECT 7210 supernatant & $48.4 \pm 30.7^{\mathrm{a}}$ & $17.0 \pm 4.1^{\mathrm{b}}$ \\
Assay positive control & $100.0 \pm 32.2$ & $100.0 \pm 33.3$ \\
Negative control QC3 & $121.7 \pm 7.14$ & $96.4 \pm 16.3$ \\
Negative control C1 & $100.0 \pm 16.1$ & $100.0 \pm 33.3$ \\
\hline
\end{tabular}

Results are the average of three different experiments and are expressed as percentage of infectious foci. SD, standard deviation; a $P$-value $<0.05$; ${ }^{b} P$ value $<0.01$. 
TABLE 3 | Inhibition of rotavirus SA11 infection in MA-104 cell line by selected reverse phase fractions following strategy $B$.

\begin{tabular}{lcc}
\hline Sample & Fraction of cationic exchange & \% Focus of infection \pm SD \\
\hline $2 / 13$ & 2 & $54.4 \pm 12.1^{\mathrm{a}}$ \\
$3 / 9$ & 3 & $56.9 \pm 29.3^{\mathrm{a}}$ \\
$3 / 10$ & 4 & $23.6 \pm 16.6^{\mathrm{b}}$ \\
$4 / 8$ & & $25.8 \pm 8.9^{\mathrm{b}}$ \\
$4 / 11$ & & $27.9 \pm 8.6^{\mathrm{b}}$ \\
$4 / 27$ & & $70.5 \pm 18.7$ \\
Control & & $100.0 \pm 10.9$
\end{tabular}

Results are the average of at least two independent experiments. SD, standard deviation; ${ }^{a} P$-value $<0.05$; ${ }^{b} P$-value $<0.001$.

the selected fractions corresponded to a peptide with a molecular weight of 1,282.63 Da. To identify the molecule with potential activity against rotavirus, the signal was identified by de novo sequencing, and the result was a peptide of 11-amino acids whose sequence was MHQPHQPLPPT (named 11-mer peptide) and whose molecular mass was $1282.63 \mathrm{Da}$ (Figure 1). This sequence was checked against the data base of proteins/peptides by means of the BLAST online tool ${ }^{1}$, and was identified as a part of the cow milk $\beta$-casein, corresponding to amino acids sequence (position 158-169; Bos taurus $\beta$-casein, GenBank accession no. AAA30431.1, gi: 162805).

${ }^{1}$ http://blast.ncbi.nlm.nih.gov/Blast.cgi

\section{Analysis of the Inhibition of Human Rotavirus Proliferation by 11-mer Peptide}

In order to determine whether 11-mer peptide was responsible for rotavirus inhibition, assays with human rotavirus $\mathrm{Wa}$, Ito, and VA70 were performed in MA-104 and HT-29 cell lines with the synthesized peptide, and following both strategy A (tested compounds were incubated with rotavirus prior to cells infection; Figure 2) and B (cells were incubated with tested compounds prior to cells infection; Figure 3). Results were different in the case of each virus and cell line. In general, inhibition percentages were higher in assays performed in MA-104 cell line. Taking into account peptide concentration, inhibition results reached a plateau at lower concentrations $(1 \mu \mathrm{M})$ and did not improve with higher peptide amounts. This result may be due to the potential formation of 11-mer peptide aggregates at higher concentrations, which leads to a loss of functionality depending on virus and cell line. For strategy A, no inhibition was obtained in VA70 assays. In the case of $\mathrm{Wa}$ virus assays, the highest inhibition percentage was $28.4 \%$ foci reduction at $1 \mu \mathrm{M} 11$-mer concentration $(p$ value $<0.001)$. In the case of Ito virus, foci reduction ranged from 33.3 and $53.7 \%$ in MA-104 cell line and from 11.6 and $26.8 \%$ in HT-29 cells. Following strategy B, Wa, Ito, and VA70 virus infections were inhibited for MA-104 cell line assays, the highest result being a $39.3 \%$ foci reduction at $5 \mu \mathrm{M} 11-\mathrm{mer}$ concentration (Wa virus). In HT-29 cells, no inhibition was obtained with Wa virus, and inhibition rendered its maximum for VA70 virus at $50 \mu \mathrm{M} 11$-mer concentration $(31.8 \%$ foci reduction, $p$-value $<0.01$ ).

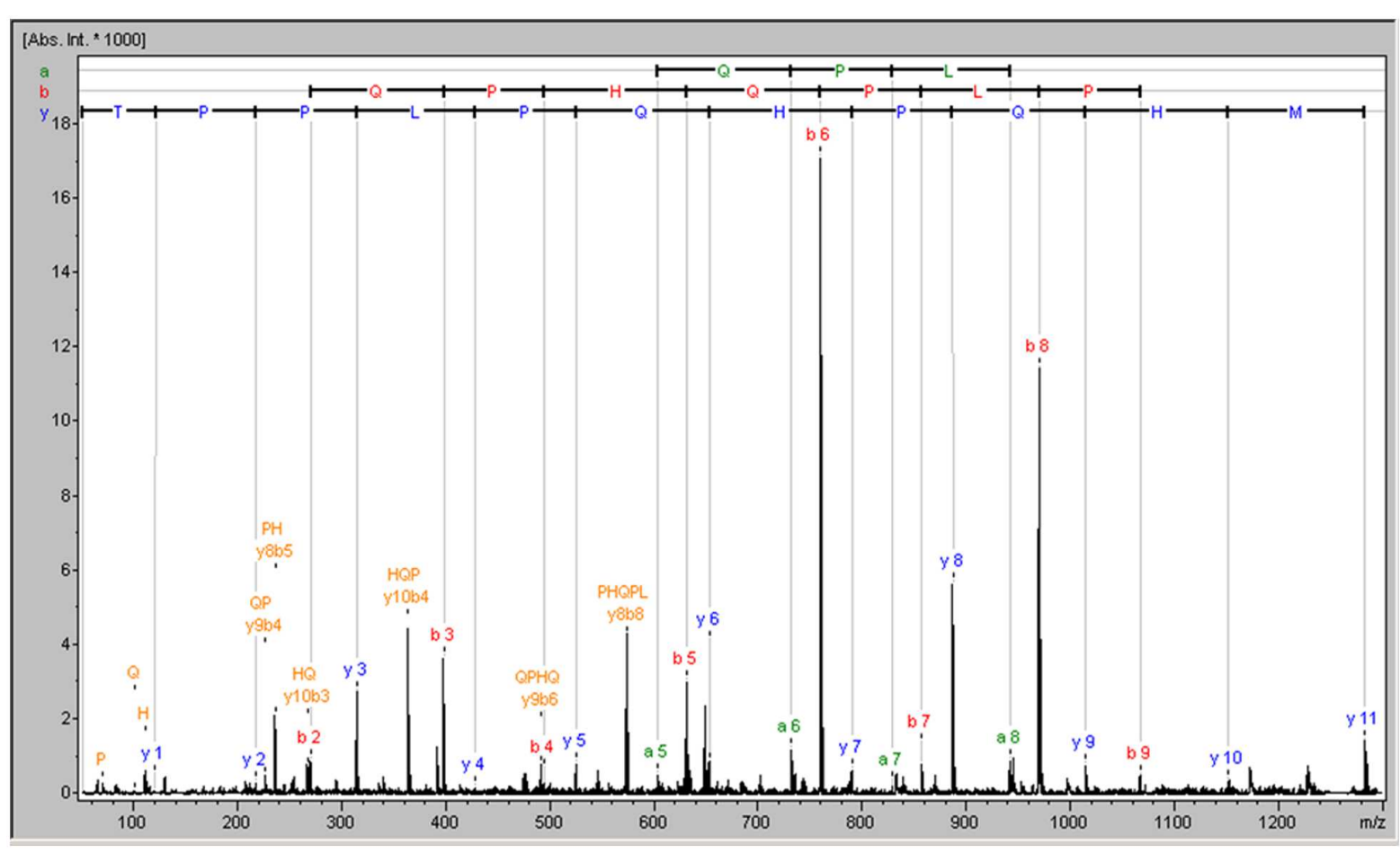

FIGURE 1 | MALDI mass spectrum of the common peptide among functional fractions obtained following purification by cationic exchange chromatography. 
A
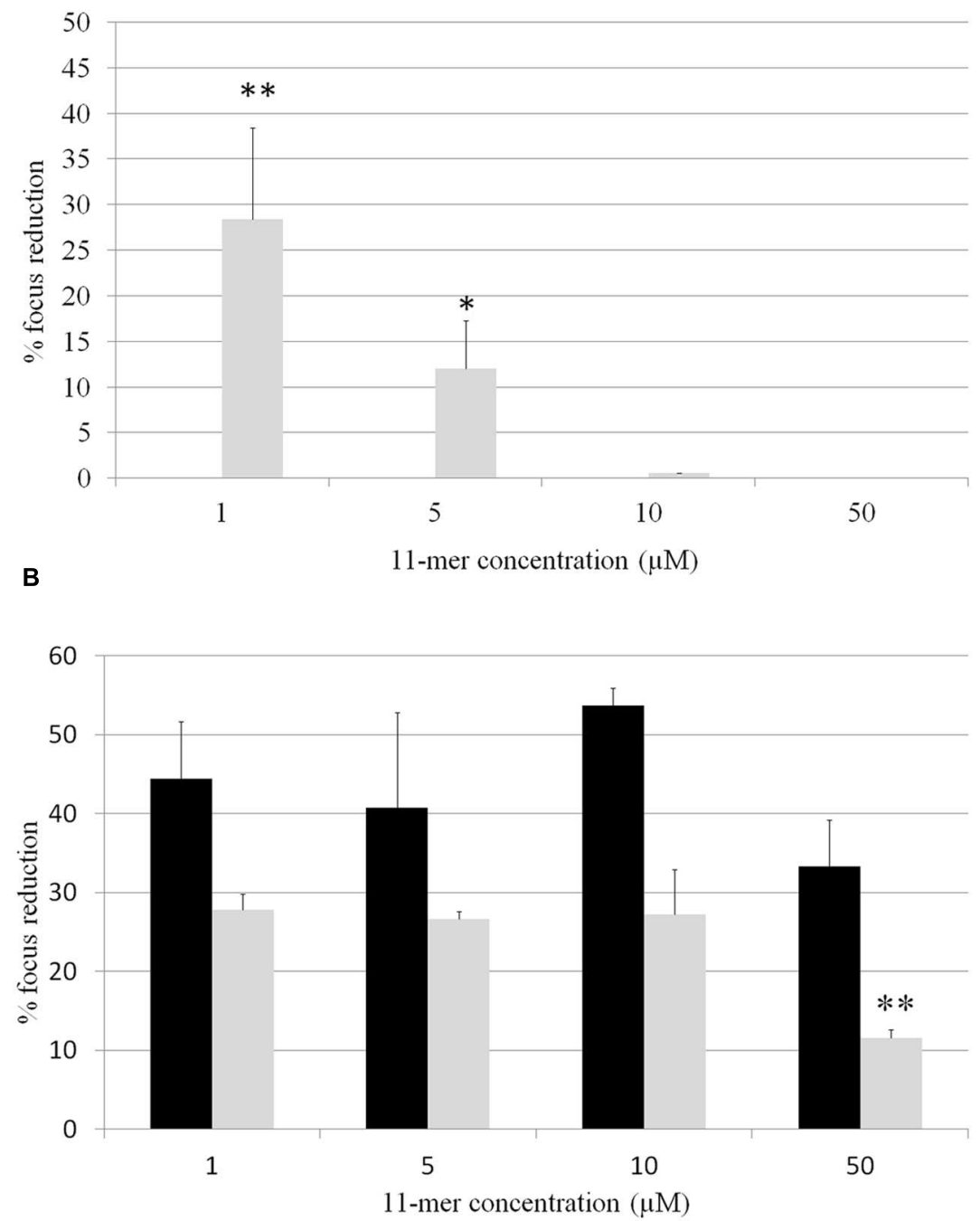

FIGURE 2 | Percentage of focus reduction in human rotavirus infection by strategy A, in which 11-mer peptide was incubated with rotavirus followed by the infection of the cells with this virus-compound mixture. Black bars correspond to MA-104 cell line and gray bars to HT-29 cell line. (A) Wa virus assays; (B) Ito virus assays. No inhibition was obtained for virus Va70. Data are the average of at least two independent experiments. Error bars represent the standard errors for replicates. ${ }^{*} P$-value $<0.05 ; * * P$-value $<0.01$.

\section{Purification and Identification of the Protease}

As human rotavirus proliferation is thought to be inhibited by the 11-mer peptide (found in cow milk $\beta$-casein), we evaluated a hypothetical mechanism whereby the peptide is released by a potential supernatant protease activity, which hydrolyses the casein present in MRS broth. To check this hypothesis, a strategy was adopted to purify and identify the potential enzyme. First of all, supernatant was chromatographically purified and the final protease-positive fraction was electrophoresed. The single $47 \mathrm{KDa}$ band present in the SDS-PAGE gel was separated and analyzed by MALDI-TOF peptide mass fingerprinting. The band was identified as "MalE-type ABC sugar transport system periplasmic component," being the highest homology with sequence gi| 189440352 (MalE-type ABC sugar transport system periplasmic component from B. longum DJO10A), which has a molecular weight of $47.155 \mathrm{KDa}$. In order to evaluate the formation of 11-mer peptide from $\beta$-casein by the activity of the purified protease, a hydrolysis assay was performed using the purified protease as enzyme and $\beta$-casein as substrate. After $48 \mathrm{~h}$ of hydrolysis, peptide quantification by HPLC showed an efficiency of $28 \pm 1 \mu \mathrm{g}$ of 11 -mer peptide/mL.

\section{Characterization of the Purified Protease}

The purified protease was characterized in terms of carbon source, $\mathrm{pH}$, temperature, and cofactors. Protease activity from B. longum CECT 7210 supernatants of media containing glucose, lactose, and maltose as sole carbon source is shown in Table 4. 
A

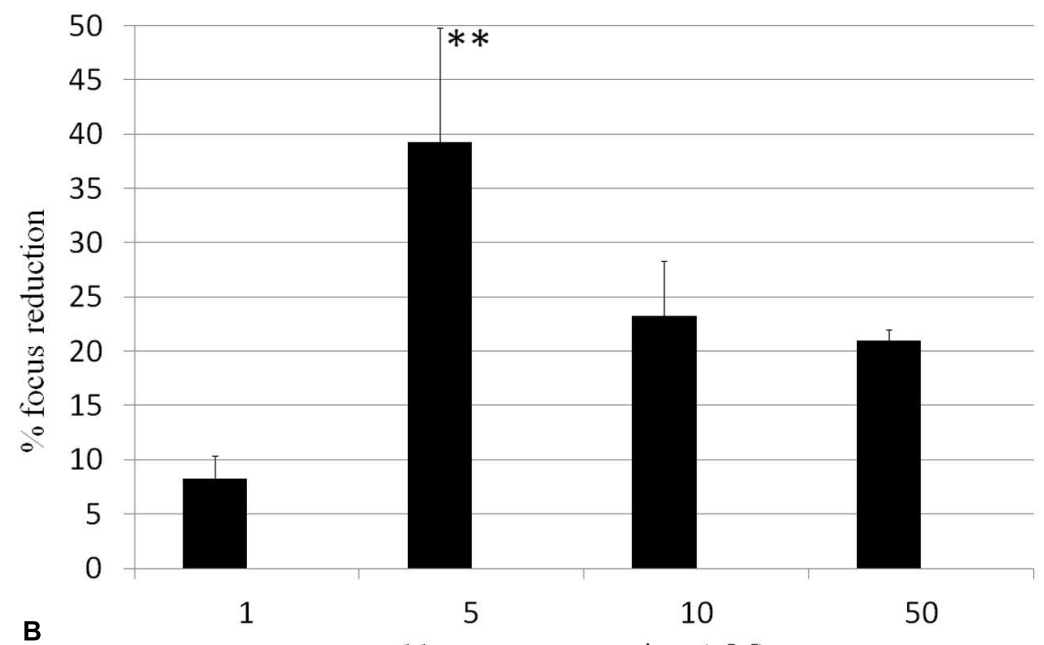

B

11-mer concentration $(\mu \mathrm{M})$

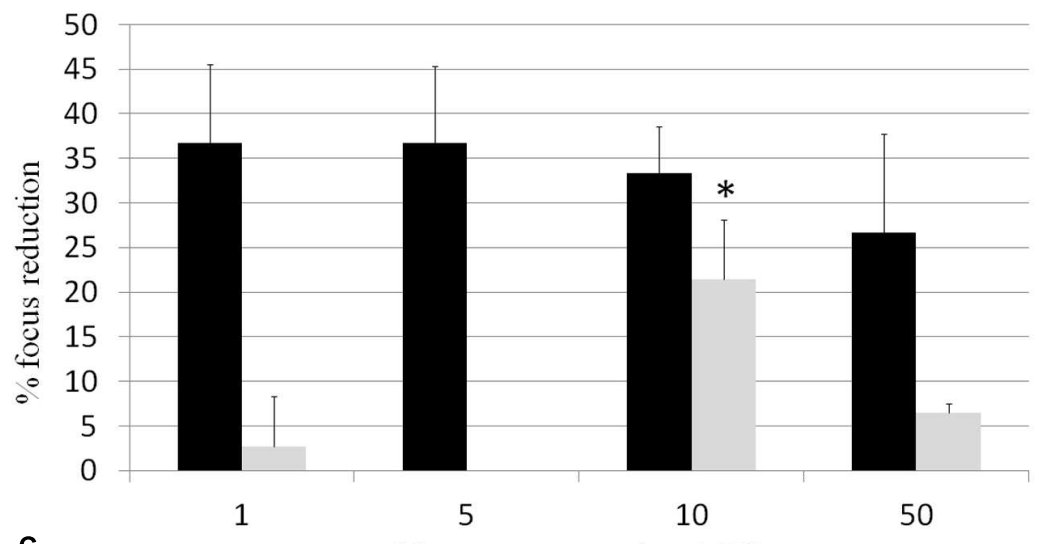

C

11-mer concentration $(\mu \mathrm{M})$

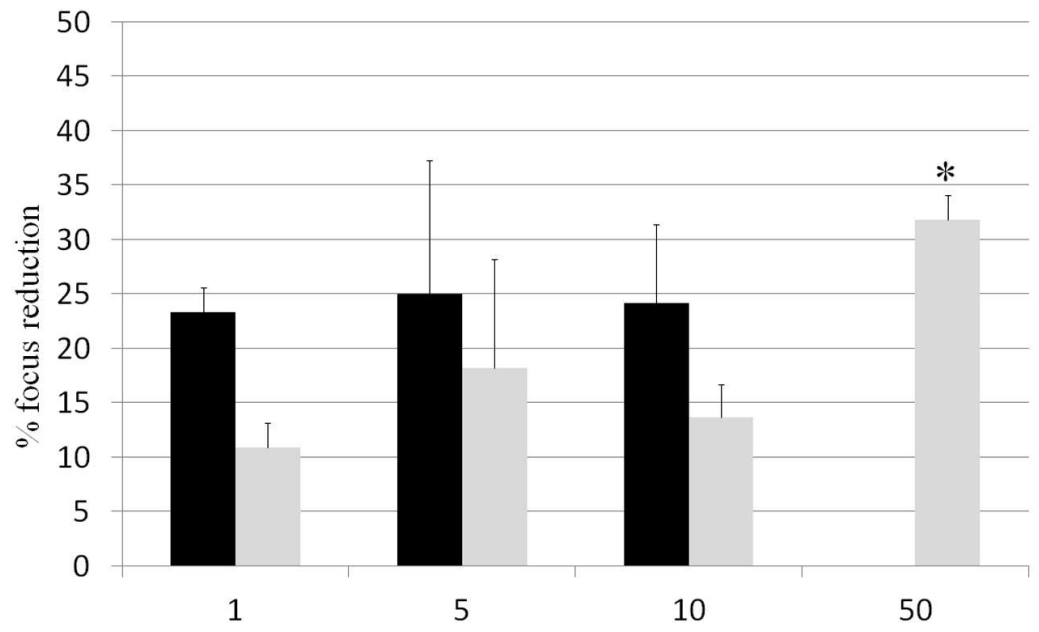

11-mer concentration $(\mu \mathrm{M})$

FIGURE 3 | Percentage of focus reduction in human rotavirus infection by strategy $B$, in which 11-mer peptide was incubated with the cell cultures followed by the inoculation of the virus. Black bars correspond to MA-104 cell line and gray bars to HT-29 cell line. (A) Wa virus assays; (B) Ito virus assays;

(C) VA70 virus assays. Data are the average of at least two independent experiments. Error bars represent the standard errors for replicates. ${ }^{*} P$-value $<0.01$; **P-value $<0.001$ 
TABLE 4 | Protease activity and 11-mer production of both supernatants and concentrated fractions (higher than 3 KDa) in supernatants obtained with the growth of $B$. longum subsp. infantis CECT 7210 in the presence of different carbohydrates, at different times of incubation.

\begin{tabular}{|c|c|c|c|c|c|c|c|}
\hline & \multicolumn{4}{|c|}{ Protease activity \pm SD $(\mathrm{mUl} / \mathrm{mL})$} & \multicolumn{3}{|c|}{$11-$ mer production $\pm \mathrm{SD}(\mu \mathrm{g} / \mathrm{mL})$} \\
\hline & Time of incubation & Glucose & Lactose & Maltose & Glucose & Lactose & Maltose \\
\hline \multirow[t]{3}{*}{ Supernatant } & $1 \mathrm{~h}$ & $1.67 \pm 1.41$ & $2.67 \pm 1.89^{a}$ & $15.33 \pm 0.94^{\mathrm{a}}$ & n.t. & n.t. & n.t. \\
\hline & $3 \mathrm{~h}$ & $1.11 \pm 1.57$ & $12.22 \pm 3.14^{b}$ & $36.11 \pm 2.36^{a}$ & n.t. & n.t. & n.t. \\
\hline & $5 \mathrm{~h}$ & $5.33 \pm 0.94$ & $9.00 \pm 0.47^{b}$ & $30.00 \pm 0.94^{a}$ & $47 \pm 4$ & $65 \pm 10$ & $90 \pm 6^{b}$ \\
\hline \multirow[t]{2}{*}{$>3 \mathrm{KDa}$ fraction } & $1 \mathrm{~h}$ & $81.67 \pm 11.36$ & $283.33 \pm 47.14^{b}$ & $973.33 \pm 202.70^{a}$ & n.t. & n.t. & n.t. \\
\hline & $2 \mathrm{~h}$ & $153.33 \pm 16.50$ & $508.33 \pm 9.43^{a}$ & $1005.83 \pm 48.31^{c}$ & $39 \pm 7$ & $73 \pm 13$ & $110 \pm 45$ \\
\hline
\end{tabular}

Results are the average of at least two different experiments. SD, standard deviation; n.t., not tested; ${ }^{\mathrm{a} P}$-value $<0.01$; ${ }^{\mathrm{b}} P$-value $<0.05$; ${ }^{\mathrm{c}} P$-value $<0.001$.

In all cases, significant higher activity was found in supernatants in which the probiotic strain B. longum CECT 7210 was grown in the presence of maltose. The supernatants rendered the highest value at $3 \mathrm{~h}$ of incubation in media with maltose, with an activity of $36.11 \mathrm{mU} / \mathrm{mL}$ ( $p$-value $<0.01)$. Regarding the purified fraction, activity values were around 28 times higher, with a maximum of $1005.83 \mathrm{mU} / \mathrm{mL}$ of activity, at $2 \mathrm{~h}$ of incubation ( $p$-value $<0.001)$. Table 4 summarizes peptide quantification obtained when supernatants and concentrated fractions were incubated with $\beta$-casein as substrate. Results ranged from 39 to $110 \mu \mathrm{g}$ of 11 -mer peptide/mL, with the highest value corresponding to supernatants and fractions obtained from the growth of probiotic CECT 7210 with maltose as sole carbon source (90 and $110 \mu \mathrm{g}$ peptide/mL, respectively).

Results regarding the effect of $\mathrm{pH}$ and temperature in 11-mer production from the purified protease are summarized in Table 5. The maximum 11-mer peptide concentration was $21 \mu \mathrm{g} / \mathrm{mL}$. This value was obtained at $\mathrm{pH} 7-8$. No significant differences were obtained at $\mathrm{pH} 4-10$. Regarding the optimum reaction temperature, values obtained ranged from 20 to $22 \mu \mathrm{g}$ of 11-mer peptide/mL, but no significant differences were found. Maximum concentration of 11 -mer peptide was obtained at $50^{\circ} \mathrm{C}$ and no activity was found at $60^{\circ} \mathrm{C}$.

In order to characterize the purified protease thoroughly, we analyzed the influence of zinc, potassium, and calcium as cofactors on 11-mer formation. Results are shown in Table 6, and ranged from 11 to $21 \mu \mathrm{g} 11$-mer peptide/mL, with the highest value corresponding to the assay without mineral addition.

TABLE 5 | Effect of pH and temperature in 11-mer production by using protease-extract as enzyme and $\beta$-casein as substrate.

$11-\operatorname{mer}(\mu \mathrm{g} / \mathrm{mL}) \pm \mathrm{SD}$

\begin{tabular}{lcccc}
\hline \multicolumn{2}{c}{ pH } & & \multicolumn{2}{c}{ Temperature } \\
$\mathrm{nnn} 4$ & $19 \pm 3$ & & $30^{\circ} \mathrm{C}$ & $21 \pm 3$ \\
$\mathrm{pH} \mathrm{6}$ & $20 \pm 4$ & & $35^{\circ} \mathrm{C}$ & $20 \pm 4$ \\
$\mathrm{pH} \mathrm{7}$ & $21 \pm 3$ & & $40^{\circ} \mathrm{C}$ & $22 \pm 5$ \\
$\mathrm{pH} \mathrm{8}$ & $21 \pm 4$ & & $50^{\circ} \mathrm{C}$ & $21 \pm 2$ \\
$\mathrm{pH} \mathrm{10}$ & $20 \pm 3$ & & $60^{\circ} \mathrm{C}$ & n.d. \\
\hline
\end{tabular}

Data are the average of at least two independent experiments. n.d., not detected.
TABLE 6 | Evaluation of the effects of zinc, calcium, and potassium addition on the production of 11-mer peptide from $\beta$-casein.

Ions

$\%$ 11-mer peptide production \pm SD

Control 100

$\mathrm{Zn}$

$\mathrm{Ca}$

$\mathrm{K}$

$57.65 \pm 1.88^{\mathrm{b}}$

$82.54 \pm 4.53^{\mathrm{a}}$

$82.63 \pm 6.03^{\mathrm{a}}$

Control has no mineral addition. Data are the average of at least two independent experiments. $S D$, standard deviation; ${ }^{a} P$-value $<0.01$; ${ }^{b} P$-value $<0.001$.

\section{DISCUSSION}

Recent clinical trials have demonstrated that some probiotic strains are able to ameliorate acute rotaviral diarrhea (Grandy et al., 2010; Lee et al., 2014). It is assumed that gut microbiota balance, the enhancement of mucosal barrier and the modulation of the immune response afford protection against rotavirus diarrhea (Kotzampassi and Giamarellos-Bourboulis, 2012). However, few studies have investigated the mechanisms underlying the protective effect of probiotics against rotavirus. A previous work demonstrated the direct effect of strain B. longum subsp. infantis CECT 7210 against rotavirus replication (Muñoz et al., 2011). Likewise, Lee et al. (2014) found that B. longum (IBG) and L. acidophilus (LA) strongly inhibited rotavirus infection using Vero cell line, but did not identify the mechanism further. In another study, Maragkoudakis et al. (2010) investigated the induction of $\mathrm{NO}$ - and $\mathrm{H}_{2} \mathrm{O}_{2}$ reactive oxygen species (ROS) released by cell lines co-incubated with lactic acid bacteria, and results were strain and cell line specific. Other data report that probiotics can block viral attachment by competitive inhibition if they are able to bind viral receptors at the surface of intestinal cells (Colbère-Garapin et al., 2007). In our study, a systematic approach was taken to identify the molecules directly involved in rotavirus inhibition.

First of all, to determine the nature of the substance of interest, supernatants with and without enzymatic treatment were analyzed for functionality. In these assays, the high percentage of inhibition of the non-treated cell-free supernatants suggested that part of the activity of CECT 7210 strain against rotavirus was not directly exerted by cells, and that the molecule responsible for direct rotavirus inhibition was released to the supernatant, as previously hypothesized for other 
probiotic strains (Botić et al., 2007). In assays performed to identify the nature of the functional compounds, treatment with different proteases eliminated inhibition capacity, confirming the proteinaceous nature of the substance responsible for inhibiting rotavirus infection. Similar assays were applied with lipases but inhibition capacity was not reduced (data not shown), refuting the potential lipidic nature of the substance of interest.

The direct effect of different compounds such as polyphenols (Kwon et al., 2010) or theaflavins (Clark et al., 1998) against rotavirus have been reported previously; however, the role played by molecules of a proteinaceous nature against rotavirus has been poorly described. In the literature, the most frequently reported protein is lactoferrin, which confers at least part of the antiviral properties of breast milk (van der Strate et al., 2001), and prevents the adsorption of rotavirus to the target cell due to its capacity to bind virus particles (Superti et al., 1997).

Once we had confirmed the proteinaceous nature of the substance acting against rotavirus, we went on to identify the active compound. We performed a supernatant purification strategy based on cationic exchange chromatography. This strategy had been carried out successfully to purify a probiotic antibacterial compound (Chenoll et al., 2011). Following this strategy, 28 fractions with cationic nature were obtained. Based on the inhibition of rotavirus infection, only six fractions were positive and thus selected for MALDI-TOF further analysis. Their spectra pointed to one functional compound, the 11amino acid peptide MHQPHQPLPPT (11-mer), common in all the positive fractions. This peptide is part of cow milk $\beta$-casein and has a molecular mass of $1.28263 \mathrm{KDa}$. In order to verify the functionality of the 11-mer peptide, inhibition assays were run with the synthesized peptide in Wa, Ito, and VA70 rotavirus using both HT-29 and MA-104 cell lines. The results were similar to those previously published with the probiotic B. longum CECT 7210 (Muñoz et al., 2011), reaching a maximum of $56 \%$ of infectious foci inhibition, and clearly confirming peptide 11-mer as being responsible for rotavirus inhibition. Reports on the direct activity of peptides against rotavirus are very scarce. Ijaz et al. (1998) found that a synthetic peptide from VP4 directly inhibited rotavirus. Their study hypothesized that VP4-peptide blocks the receptor sites on the host cells. In other studies, Kvistgaard et al. (2004) and Bojsen et al. (2007) found that some bovine macromolecular whey proteins may exert in vitro and in vivo inhibitory activity against rotavirus, the major component being bovine IgG. Regarding lactoferrin, few peptides have been reported. Superti et al. (1997) used different peptides coming from artificially hydrolyzed lactoferrin to demonstrate that some peptides are able to interfere with different stages in virus replication, and the importance of specific recognition events. Regarding casein as the source of antiviral activity, previous work in bovine milk demonstrated the antiviral activity of $\kappa$-casein against human rotavirus and concluded that the inhibitory mechanism of bovine $\kappa$-casein against human rotavirus involves direct binding to viral particles via glycan residues (Inagaki et al., 2014). In our case, the 11-mer peptide does not contain glycan residues, and furthermore, its antiviral activity is conserved with synthesized peptide (with no glycan residues). Therefore, another mechanism must be involved in its activity against rotavirus. The facts that the peptide was effective in assays carried out with both strategies (A and B), and that we found different sensitivities depending on the virus and cell line, strongly suggest a two-way effect, in which the interaction of the peptide with both the mammalian cell surface and directly with the virus, must play a role in the inhibition mechanism, as hypothesized previously (Muñoz et al., 2011). Moreover, positive results were obtained even at low peptide concentrations $(1 \mu \mathrm{M})$, showing the peptide exerts a strong activity.

To identify the source of the 11-mer peptide, the analysis of all the experimental data lead us to hypothesize a secondary origin of the peptide, derived from the preliminary digestion of casein present in the commercial MRS growth medium used. A protease secreted by the probiotic strain B. longum subsp. infantis CECT 7210 may release 11-mer peptide by hydrolyzing the casein present in the culture. A mechanism by which functional molecules are released from casein was previously described by Janer et al. (2005) in B. animalis subsp. lactis species. These authors described a zinc metallopeptidase (PepO) able to hydrolyze $\alpha_{\mathrm{s} 1}$-casein (f1-23), which was suggested to play a role in the increased growth of $B$. animalis subsp. lactis in milk. Accordingly, we performed the purification and identification of the protease responsible for 11-mer production. To obtain the protease, we applied a strategy based on fractionation by anionic chromatography. Following this protocol, a protease-positive anionic extract was obtained, and a SDS-gel band confirmed a unique band. MALDI-TOF peptide mass fingerprinting analysis identified the purified protease as "MalE-type ABC sugar transport system periplasmic component." This is a periplasmic binding protein, part of the Maltose $\mathrm{ABC}$ sugar transport system, which is involved in the transport of maltose and maltodextrins. Although preliminary studies with this component were performed in Salmonella enterica subsp. enterica serovar Typhimurium and Escherichia coli (reviewed in Ehrmann et al., 1998), it has been found in other bacteria, including bifidobacteria (Balac_0483 in assembly NC_012814.1 from B. animalis subsp. lactis Bl04, BLD_1008 in assembly ACD98454.1 from B. longum DJO10A). With the data obtained by the whole genome sequencing of B. longum CECT 7210 strain (Chenoll et al., 2015; genome reference LN824140), the protein has been identified in its genome, with a molecular weight of $46.89 \mathrm{KDa}$, confirming that the protein is produced by this probiotic strain. Once identified, the MalE-type $A B C$ sugar transport system periplasmic component was characterized in terms of its protease activity. The results obtained in inhibition studies with glucose, lactose, and maltose supernatants showed the highest activity when the probiotic was grown in maltose as the only carbon source. Moreover, maltose-grown purified fractions were around 28 times higher, with a maximum of $1000 \mathrm{mU} \mathrm{mL} \mathrm{m}^{-1}$ of activity. These results, together with the quantification of 11-mer peptide when these supernatants and fractions were incubated with $\beta$-casein, confirmed that protease activity is enhanced when maltose is the sole carbon source. This 
supports the identification of the MalE-type ABC sugar transport system periplasmic component as the molecule responsible for this protease activity. Although protease activity in MalE has not been described previously, our data point to a mechanism whereby the formation of the 11-mer peptide from $\beta$-casein is caused by the direct action of the purified protein, with an efficiency of $28 \pm 1 \mu \mathrm{g} / \mathrm{mL}$ of reaction. Finally, optimum $\mathrm{pH}$ and temperature for purified protease activity have been established and the influence of zinc, potassium, and calcium as cofactors on 11-mer production discarded.

To our knowledge, this is the first report of a mechanism by which a probiotic produces a functional molecule exerting a direct activity against rotavirus. This mode of action supports the potential use of strain CECT 7210 in dairy infant formulas, in which functional peptide 11-mer would be produced by the probiotic from cow milk $\beta$-casein.

In summary, the results presented here are the first to identify a naturally produced peptide, the 11-mer (MHQPHQPLPPT), as the molecule directly responsible for rotavirus inhibition demonstrated by the probiotic B. longum subsp. infantis CECT 7210. The data reported here point to a mechanism based on the MalE-type ABC sugar transport system periplasmic component, which is able to exert a protease activity and to hydrolyze $\beta$-casein to produce the functional 11-mer peptide.

\section{REFERENCES}

Bojsen, A., Buesa, J., Montava, R., Kvistgaard, A. S., Kongsbak, M. B., Petersen, T. E., et al. (2007). Inhibitory activities of bovine macromolecular whey proteins on rotavirus infections in vitro and in vivo. J. Dairy Sci. 90, 66-74. doi: 10.3168/jds.S0022-0302(07)72609-7

Botić, T., Klingberg, T. D., Weingartl, H., and Cencič, A. (2007). A novel eukaryotic cell culture model to study antiviral activity of potential probiotic bacteria. Int J. Food Microbiol. 115, 227-234. doi: 10.1016/j.ijfoodmicro.2006.10.044

Bradford, M. M. (1976). A rapid and sensitive method for the quantitation of microgram quantities of protein utilizing the principle of protein-dye binding. Anal. Biochem. 72, 248-254. doi: 10.1016/0003-2697(76)90527-3

Bucardo, F., Mercado, J., Reyes, Y., González, F., Balmaseda, A., and Nordgren, J. (2015). Large increase of rotavirus diarrhea in the hospital setting associated with emergence of G12 genotype in a highly vaccinated population in Nicaragua. Clin. Microbiol. Infect. 21, 603.e1-603.e7. doi: 10.1016/j.cmi.2015.01.022

Cao, M., Yang, M., Ou, Z., Li, D., Geng, L., Chen, P., et al. (2014). Involvement of aquaporins in a mouse model of rotavirus diarrhea. Virol. Sin. 29, 211-217. doi: 10.1007/s12250-014-3469-Z

Chenoll, E., Casinos, B., Bataller, E., Astals, P., Echevarría, J., Iglesias, J. R., et al. (2011). Novel probiotic Bifidobacterium bifidum CECT 7366 strain active against the pathogenic bacterium Helicobacter pylori. Appl. Environ. Microbiol. 77, 1335-1343. doi: 10.1128/AEM.01820-10

Chenoll, E., Rivero, M., Codoñer, F. M., Martinez, J. F., Ramón, D., Genovés, S., et al. (2015). Complete genome sequence of Bifidobacterium longum subsp. infantis strain CECT 7210, a probiotic strain active against rotavirus infections. Genome Announc. 3:e00105-15. doi: 10.1128/genomeA.00105-15

Clark, K. J., Grant, P. G., Sarr, A. B., Belakere, J. R., Swaggerty, C. L., Philips, T. D., et al. (1998). An in vitro study of theaflavins extracted from black tea to neutralize bovine rotavirus and bovine coronavirus infections. Vet. Microbiol. 63, 147-157. doi: 10.1016/S0378-1135(98)00242-9

Colbère-Garapin, F., Martin-Latil, S., Blondel, S., Mousson, L., Pelletier, I., Autret, A., et al. (2007). Prevention and treatment of enteric viral infections:

\section{AUTHOR CONTRIBUTIONS}

EC designed the experiments, participated in assays for hydrolyzing, fractioning, and identification of the supernatant molecules with protease and antirotaviral activity, and contributed to data-analysis and writing. BC participated in all the experiments. EB participated in hydrolyzing, supernatant fractioning, and identification of the protease experiments. JB designed and coordinated virus experiments and contributed to data-analysis and writing. DR designed and coordinated supernatant protease experiments, and contributed to dataanalysis and writing. SG designed and coordinated protease and supernatants experiments, and contributed to data-analysis and writing. JF contributed to data-analysis and writing. MR participated in the design of experiments, and contributed to data-analysis and writing. JM designed the research plan and organized the study, and contributed to data-analysis and writing.

\section{FUNDING}

This study was supported by Ministerio de Industria, Turismo y Comercio grant PROFIT (FIT-0600000-2006-22), and the European Social Fund (grants PTQ06-2-0642 and PTQ050101208). JM was co-funded by an ICREA Junior Empresa Grant (Catalonia, Spain).

possible benefits of probiotic bacteria. Microbes Infect. 9, 1623-1631. doi: 10.1016/j.micinf.2007.09.016

Demirjian, A., and Levy, O. (2009). Safety and efficacy of neonatal vaccination. Eur. J. Immunol. 39, 36-46. doi: 10.1002/eji.200838620

Dennehy, P. H. (2008). Rotavirus vaccines: an overview. Clin. Microbiol. Rev. 21, 198-208. doi: 10.1128/CMR.00029-07

Ehrmann, M., Ehrle, R., Hofmann, E., Boos, W., and Schlösser, A. (1998). The ABC maltose transporter. Mol. Microbiol. 29, 685-694. doi: 10.1046/j.13652958.1998.00915.x

FAO/WHO (2001). Report of a Joint FAO/WHO Expert Consultation on Evaluation of Health and Nutritional Properties of Probiotics in Food Including Powder Milk with Live Lactic Acid Bacteria. Córdoba: Food and Agriculture Organization of the United Nations.

Glass, R. I., Parashar, U., Patel, M., Gentsch, J., and Jiang, B. (2014). Rotavirus vaccines: successes and challenges. J. Infect. 68(Suppl. 1), S9-S18. doi: 10.1016/j.jinf.2013.09.010

Grandy, G., Medina, M., Soria, R., Terán, C. G., and Araya, M. (2010). Probiotics in the treatment of acute rotavirus diarrhea. A randomized, double-blind, controlled trial using two different probiotic preparations in Bolivian children. BMC Infect. Dis. 10:253. doi: 10.1186/1471-233410-253

Hagbom, M., Sharma, S., Lundgren, O., and Svensson, L. (2012). Towards a human rotavirus disease model. Curr. Opin. Virol. 2, 408-418. doi: 10.1016/j.coviro.2012.05.006

Hodges, K., and Gill, R. (2010). Infectious diarrhea. Cell. Mol. Mech. Gut Microbes 1, 4-21. doi: 10.4161/gmic.1.1.11036

Ijaz, M. K., Nur-E-Kamal, M. S., Dar, F. K., Uduman, S., Redmond, M. J., AttahPoku, S. K., et al. (1998). Inhibition of rotavirus infection in vitro and in vivo by a synthetic peptide from VP4. Vaccine 16, 916-920. doi: 10.1016/S0264410X(97)00298-3

Inagaki, M., Muranishi, H., Yamada, K., Kakehi, K., Uchida, K., Suzuki, T., et al. (2014). Bovine $\kappa$-casein inhibits human rotavirus (HRV) infection via direct binding of glycans to HRV. J. Dairy Sci. 97, 2653-2661. doi: 10.3168/jds.20137792 
Istrate, C., Hagbom, M., Vikström, E., Magnusson, K. E., and Svensson, L. (2014). Rotavirus infection increases intestinal motility but not permeability at the onset of diarrhea. J. Virol. 88, 3161-3169. doi: 10.1128/JVI. 02927-13

Janer, C., Arigoni, F., Lee, B. H., Peláez, C., and Requena, R. (2005). Enzymatic ability of Bifidobacterium animalis subsp. lactis to hydrolyze milk proteins: identification and characterization of endopeptidase. Appl. Environ. Microbiol. 72, 8460-8465. doi: 10.1128/AEM.71.12.8460-8465.2005

Kapikian, A. Z., Hoshino, Y., and Chanock, R. M. (2001). "Rotaviruses," in Fields Virology, 4th Edn, eds D. M. Knipe and P. M. Howley (Philadelphia, PA: Lippincott-Raven), 1787-1833.

Kotzampassi, K., and Giamarellos-Bourboulis, E. J. (2012). Probiotics for infectious diseases: more drugs, less dietary supplementation. Int. J. Antimicrob. Agents 40, 288-296. doi: 10.1016/j.ijantimicag.2012.06.006

Kvistgaard, A. S., Pallesen, L. T., Arias, C. F., López, S., Petersen, T. E., Heegaard, C. W., et al. (2004). Inhibitory effects of human and bovine milk constituents on rotavirus infections. J. Dairy Sci. 87, 4088-4096. doi: 10.3168/jds.S00220302(04)73551-1

Kwon, H.-J., Kim, H.-H., Ryu, Y. B., Kim, J. H., Jeong, H. J., Lee, S.-W., et al. (2010). In vitro anti-rotavirus activity of polyphenol compounds isolated from the roots of Glycyrrhiza uralensis. Bioorg. Med. Chem. 18, 7668-7674. doi: 10.1016/j.bmc.2010.07.073

Lee, D. K., Park, J. E., Kim, M. J., Seo, J. G., Lee, J. H., and Ha, N. J. (2014). Probiotic bacteria, B. longum and L. acidophilus inhibit infection by rotavirus in vitro and decrease the duration of diarrhea in pediatric patients. Clin. Res. Hepatol. Gastroenterol. 12, S2210-S7401. doi: 10.1016/j.clinre.2014. 09.006

Lopman, B. A., Curns, A. T., Yen, C., and Parashar, U. D. (2011). Infant rotavirus vaccination may provide indirect protection to older children and adults in the United States. J. Infect. Dis. 204, 980e6. doi: 10.1093/infdis/jir492

Lundgren, O., Peregrinm, A. T., Persson, K., Kordasti, S., Uhnoo, I., and Svensson, L. (2000). Role of the enteric nervous system in the fluid and electrolyte secretion of rotavirus diarrhea. Science 287, 491-495. doi: 10.1126/science.287.5452.491

Maragkoudakis, P. A., Chingwaru, W., Gradisnik, L., Tsakalidou, E., and Cencic, A. (2010). Lactic acid bacteria efficiently protect human and animal intestinal epithelial and immune cells from enteric virus infection. Int. J. Food Microbiol. 141, S91-S97. doi: 10.1016/j.ijfoodmicro.2009.12.024

Muñoz, J. A., Chenoll, E., Casinos, B., Bataller, E., Ramón, D., Genovés, S., et al. (2011). Novel probiotic Bifidobacterium longum subsp. infantis CECT
7210 strain active against rotavirus infections. Appl. Environ. Microbiol. 77, 8775-8783. doi: 10.1128/AEM.05548-11

Oelschlaeger, T. A. (2010). Mechanisms of probiotic actions: a review. Int. J. Med. Microbiol. 300, 57-62. doi: 10.1016/j.ijmm.2009.08.005

Parashar, U. D., Gibson, C. J., Bresee, M. A., and Glass, R. I. (2006). Rotavirus and severe childhood diarrhea. Emerg. Infect. Dis. 12, 304-306. doi: 10.3201/eid1202.050006

Reid, G. (2008). Probiotic lactobacilli for urogenital health in women. J. Clin. Gastroenterol. 42(Suppl.), S234-S236. doi: 10.1097/MCG.0b013e31817f1298

Sindhu, K. N., Sowmyanarayanan, T. V., Pau, A., Babji, S., Ajjampur, S. S., Priyadarshini, S., et al. (2014). Immune response and intestinal permeability in children with acute gastroenteritis treated with Lactobacillus rhamnosus GG: a randomized, double-blind, placebo-controlled trial. Clin. Infect. Dis. 58, 1107-1115. doi: 10.1093/cid/ciu065

Superti, F., Ammendolia, M. G., Valenti, P., and Seganti, L. (1997). Antirotaviral activity of milk proteins: lactoferrin prevents rotavirus infection in the enterocyte-like cell line HT-29. Med. Microbiol. Immunol. 186, 83-91. doi: 10.1007/s004300050049

van der Strate, B. W. A., Beljaars, L., Molema, G., Harmsen, M. C., and Meijer, D. K. F. (2001). Antiviral activities of lactoferrin. Antiviral Res. 52, 225-239. doi: 10.1016/S0166-3542(01)00195-4

Vesikari, T., Karvonen, A., Prymula, R., Schuster, V., Tejedor, J. C., Cohen, R., et al. (2007). Efficacy of human rotavirus vaccine against rotavirus gastroenteritis during the first 2 years of life in European infants: randomised, double-blind controlled study. Lancet 370, 1757-1763. doi: 10.1016/S0140-6736(07)61744-9

Williams, C. J., Lobanov, A., and Pebody, R. G. (2009). Estimated mortality and hospital admission due to rotavirus infection in the WHO European region. Epidemiol. Infect. 137, 607-616. doi: 10.1017/S0950268808001714

Conflict of Interest Statement: This work was partially funded by Laboratorios Ordesa. JF, MR, and JM are employees of Laboratorios Ordesa. EC, BC, DR, and SG are employees of Biopolis.

Copyright (C) 2016 Chenoll, Casinos, Bataller, Buesa, Ramón, Genovés, Fábrega, Rivero Urgell and Moreno Muñoz. This is an open-access article distributed under the terms of the Creative Commons Attribution License (CC BY). The use, distribution or reproduction in other forums is permitted, provided the original author(s) or licensor are credited and that the original publication in this journal is cited, in accordance with accepted academic practice. No use, distribution or reproduction is permitted which does not comply with these terms. 